\title{
Eating disorders mothers and their children: a systematic review of the literature
}

\author{
Maria Giulia Martini $^{1,2}$ • Manuela Barona-Martinez ${ }^{1}$ • Nadia Micali ${ }^{1,3,4}$
}

Received: 30 July 2019 / Accepted: 7 January 2020 / Published online: 14 January 2020

(C) The Author(s) 2020

\begin{abstract}
To provide an overview of the impact of maternal eating disorders (ED) on child development in a number of domains including feeding and eating behaviour, neuropsychological profile and cognitive development, psychopathology and temperament. PubMed, Embase and PsychInfo were searched for studies exploring the impact of maternal ED on children between January 1980 and September 2018. Initial search yielded 569 studies. After exclusion, 32 studies were reviewed. Overall, available evidence shows that children of mothers with ED are at increased risk of disturbances in several domains. They exhibit more difficulties in feeding and eating behaviours, display more psychopathological and socio-emotional difficulties, and they are more likely to be described as having a difficult temperament. Maternal ED have an impact on child psychological, cognitive and eating behaviours, and might affect the development of ED in the offspring. Future research should focus on resilience and on which protective factors might lead to positive outcomes. These factors can be then used as therapeutic and preventative targets.
\end{abstract}

Keywords Eating disorder · Intergenerational effect $\cdot$ Children $\cdot$ Mothers

\section{Introduction}

Eating disorders (ED) are mental health disorders characterised by severe disturbances in eating behaviour that significantly impact an individual's emotional, psychosocial and physical well-being (Bannatyne et al. 2018). Current diagnostic classifications of ED include anorexia nervosa (AN), bulimia nervosa (BN) and binge-eating disorder (BED) as full threshold ED. ED typically affect women of reproductive age (Easter et al. 2014).

Early childhood is a crucial time for the development of the mother-child relationship. It is during this time that children

Maria Giulia Martini

m.martini@ucl.ac.uk; mgmartini@hotmail.it

1 Behavioural and Brain Sciences Unit, Institute of Child Health, University College London, 4th Floor, 30 Guilford Street, London WC1N 1EH, UK

2 South London and Maudsley, NHS Foundation Trust, London, UK

3 Department of Psychiatry, University of Geneva, Geneva, Switzerland

4 Child and Adolescent Psychiatry Division, Department of Child and Adolescent Health, University Hospital Geneva, Geneva, Switzerland develop psychosocially, engage in social learning and express their temperament - which is a biological tendency within each child but it is shaped by complex interactions between genetic, biological and environmental factors (Shiner et al. 2012).

Risk for developmental problems in children of women with psychiatric disorder has been well documented in literature and several aspects of children's development can be affected, including their physical, cognitive, social, emotional and behavioural development (Ramchandani and Stein 2003). Fewer studies are available regarding the impact of ED on child development.

However, the literature available suggests that children of mothers with ED have an increased risk for negative developmental outcomes, including cognitive, social and emotional disturbances (Patel et al. 2002). Research has shown that children of mothers with ED are more likely to develop an emotional disorder at the age of 7 and 10 (Micali et al. 2014a), they are more likely to show neurobehavioural dysregulation early after birth and poorer language and motor development at 1 year (Barona et al. 2017).

Furthermore, there is evidence that children of mothers with ED are more likely to develop ED themselves (Kothari et al. 2013).

Family and twin studies have consistently demonstrated that ED have a strong genetic component (Mazzeo et al. 
2005); however, the environment is likely to play a crucial role in the expression of underlying genetic predispositions.

In 2005, Bulik et al. (2005) proposed a cycle of risk model for the development of AN, whereby the maternal effect of AN on their children via perinatal complications is hypothesised as being influenced by environmental factors, genetic factors and environmental factors that are highly influenced by maternal genotype (i.e. pregnancy nutrition, weight gain in utero, appearance focus and restrictive eating during childhood/adolescence). In 2009, Micali and Treasure suggested a risk model for the impact of maternal ED on child development that embraces all ED focusing on in utero mechanisms. In particular, the model explained the effect of a maternal ED in pregnancy on the foetus via nutritional factors (including protein deficiency, low folate and low iron intake) and comorbid psychopathology (i.e. comorbid anxiety and depression and in turn via increased glucocorticoids and corticotrophin-releasing hormone) which both could lead to obstetric complications (Micali and Treasure 2009). The influence of parental ED on child phenotype might likely be the result of a complex interplay between genetic (maternal and child) and environmental factors.

Understanding the mechanisms leading from maternal ED to adverse child development could help to determine both risk and protective factors that could be potentially targeted for intervention.

To date, only one recent systematic review has been published on this topic in the last several years and the authors did focus only on the most recent findings (2015 onwards) (Watson et al. 2018). Previous reviews focusing on children of mothers with ED include (Patel et al. 2002) and (Park et al. 2003). No systematic reviews have been carried out so far covering the period between 2003 and 2015 and many relevant populationbased studies have been carried out over this period.

The purpose of our paper is to provide an overview of the impact of maternal ED on child development. Particularly, this review will focus on effects on developmental aspects, across the spectrum of feeding and eating behaviour, neuropsychological profile and cognitive development, psychopathology and temperament.

\section{Methods and materials}

\section{Data source}

A systematic and comprehensive search of databases, including PsychInfo, Embase and Medline, was carried out for studies published between January 1980 and September 2018. The search was performed using the following mesh terms and keywords: ('maternal eating disorders' or 'maternal anorexia nervosa' or 'maternal bulimia nervosa' or 'maternal binge eating disorder' or 'mothers with eating disorders' or 'mothers with anorexia nervosa' or 'mothers with bulimia nervosa' or 'mothers with binge eating disorder') and ('child development' or 'child language development' or 'child feeding' or 'child cognitive development' or 'child temperament' or 'child psychopathology').

\section{Study selection}

Inclusion criteria for the studies included (1) exposure (mothers) diagnosed with any ED (i.e. AN, BN and BED) either active or past, (2) the outcome was a measure of child development assessed from birth up until 12 years of age, (3) studies published in English and (4) primary studies.

Exclusion criteria for the studies included the following: studies were excluded if the aims were to investigate child eating pathology. Papers were also excluded if an intervention was assessed such as video-feedback interactional treatment.

\section{Quality assessment and data extraction}

Two authors (M.G.M. and M.B.) independently screened, extracted and cross-checked the data based on a priori exclusion and inclusion criteria. The quality of the final studies was also independently checked by both authors using the NewcastleOttawa Scale (NOS) for assessing the quality of nonrandomised studies in meta-analyses (Table 1). The above scale includes case-control and cohort studies.

For each study, the following data were extracted when available: demographic information, including participant characteristics (sample size ad mean age), ED type (AN, $\mathrm{BN}, \mathrm{BED}$ ), ED status (actual vs. recovered); measures used to certain exposure and outcome. The identified studies investigated a number of different child outcomes. After discussion between authors (M.B., M.G.M., N.M.), four domains were discussed: feeding/eating, neuropsychological profile/ cognitive development, psychopathology and temperament. However, a range of studies investigated more than one outcome and were included in more than one domain (Table 1).

\section{Results}

\section{Search findings}

A PRISMA flow diagram presents all phases of the review (Fig. 1) (Moher et al. 2009).

Most studies used case-control $(n=17)$ and cohort design $(n=16)$ and one early study used an uncontrolled design. The majority of studies were published within the last decade $(n=$ 25) with 59\% published within the last 5 years (2013-2018).

Studies included measured various aspects of child development: feeding/eating $(n=17)$, cognitive development/ neuropsychological profile $(n=6)$, psychopathology $(n=12)$ 


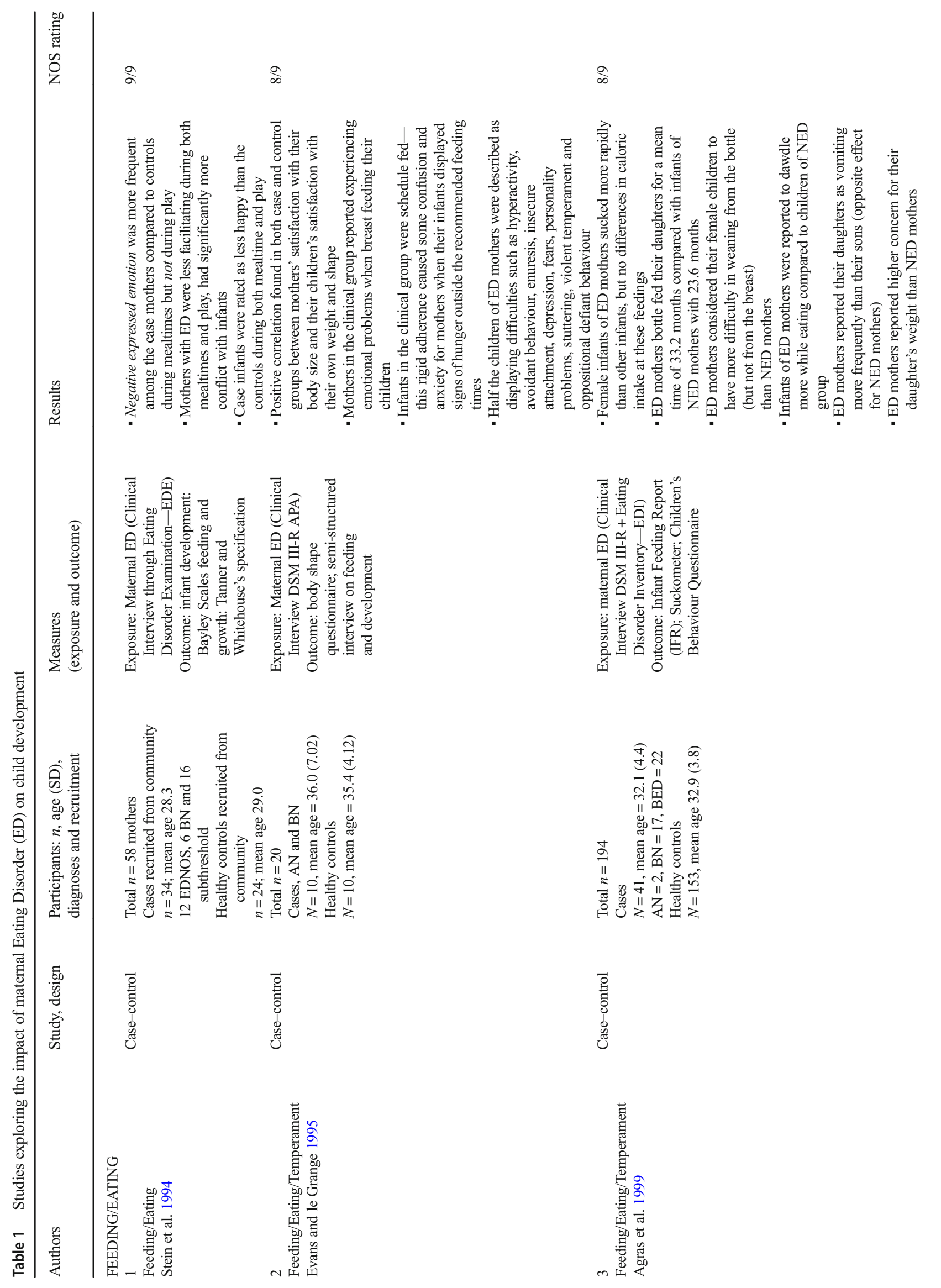




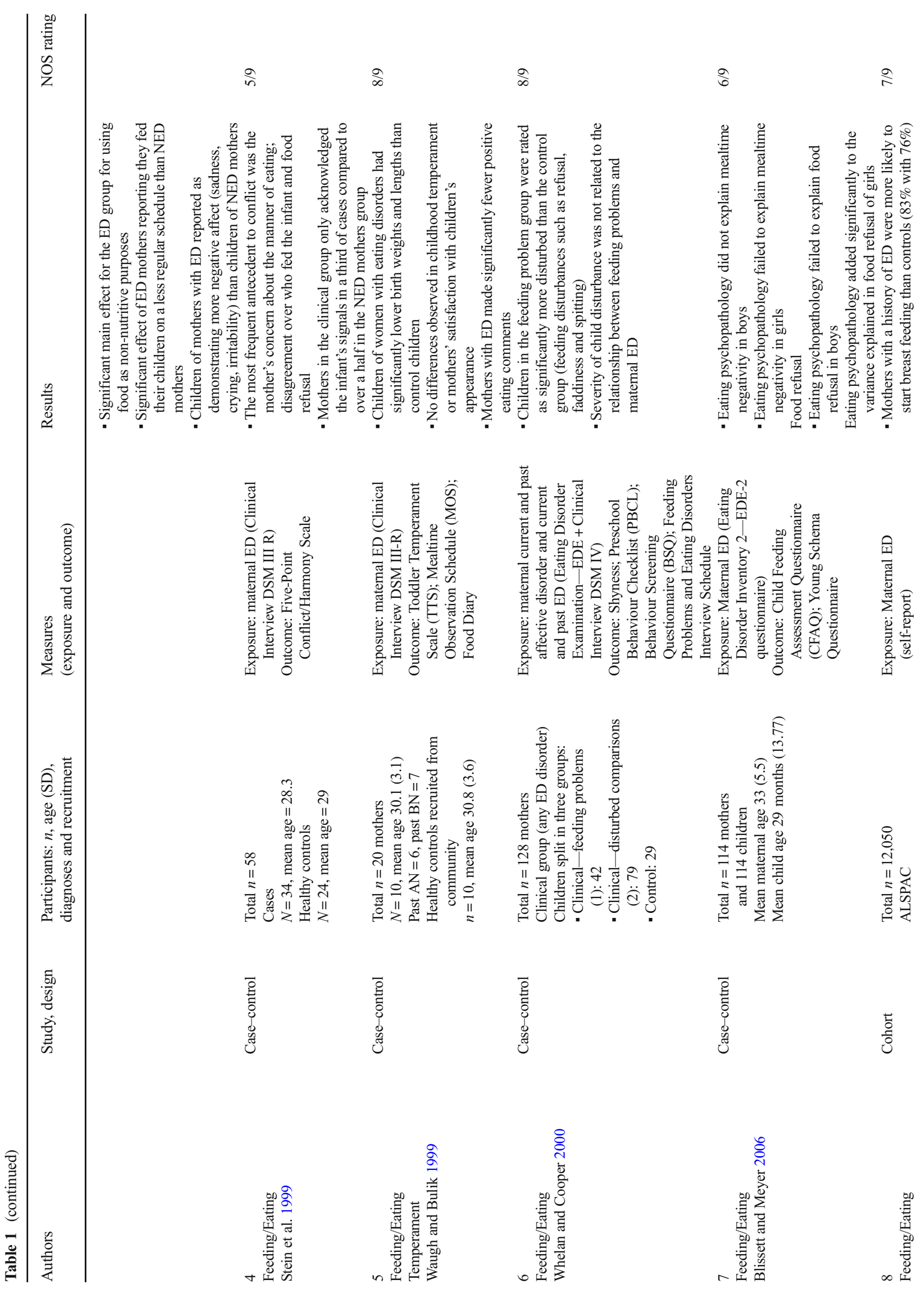




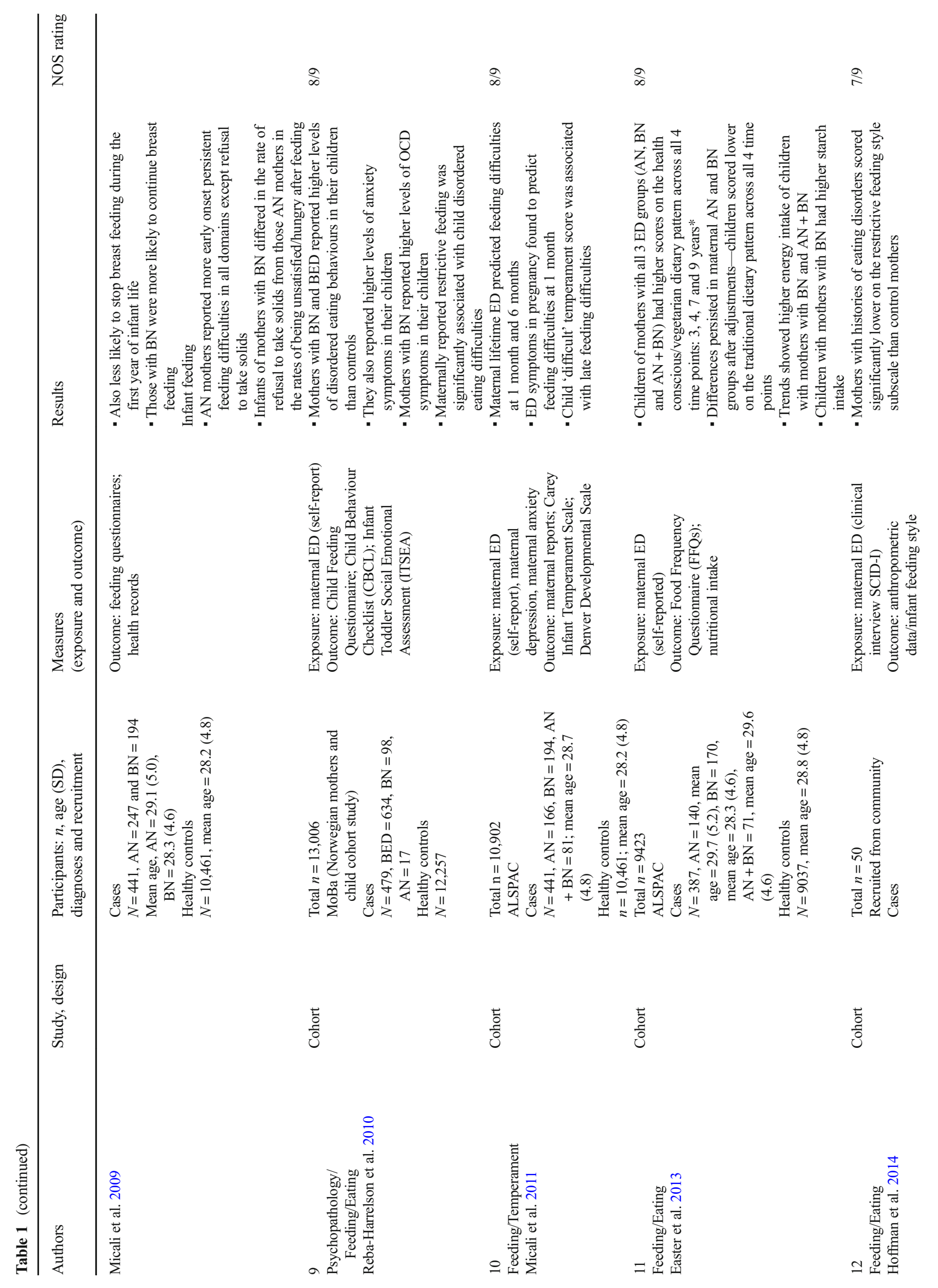




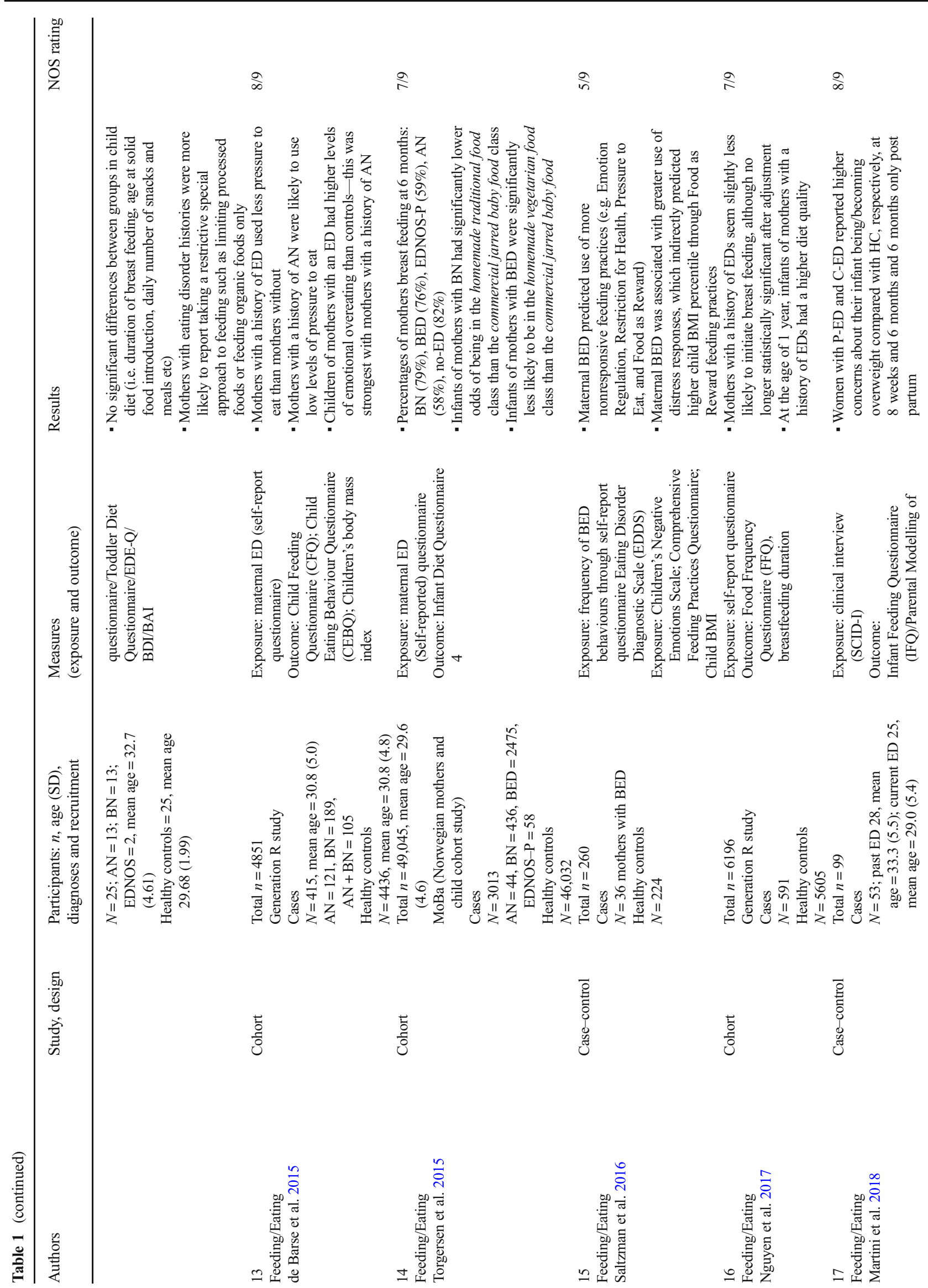




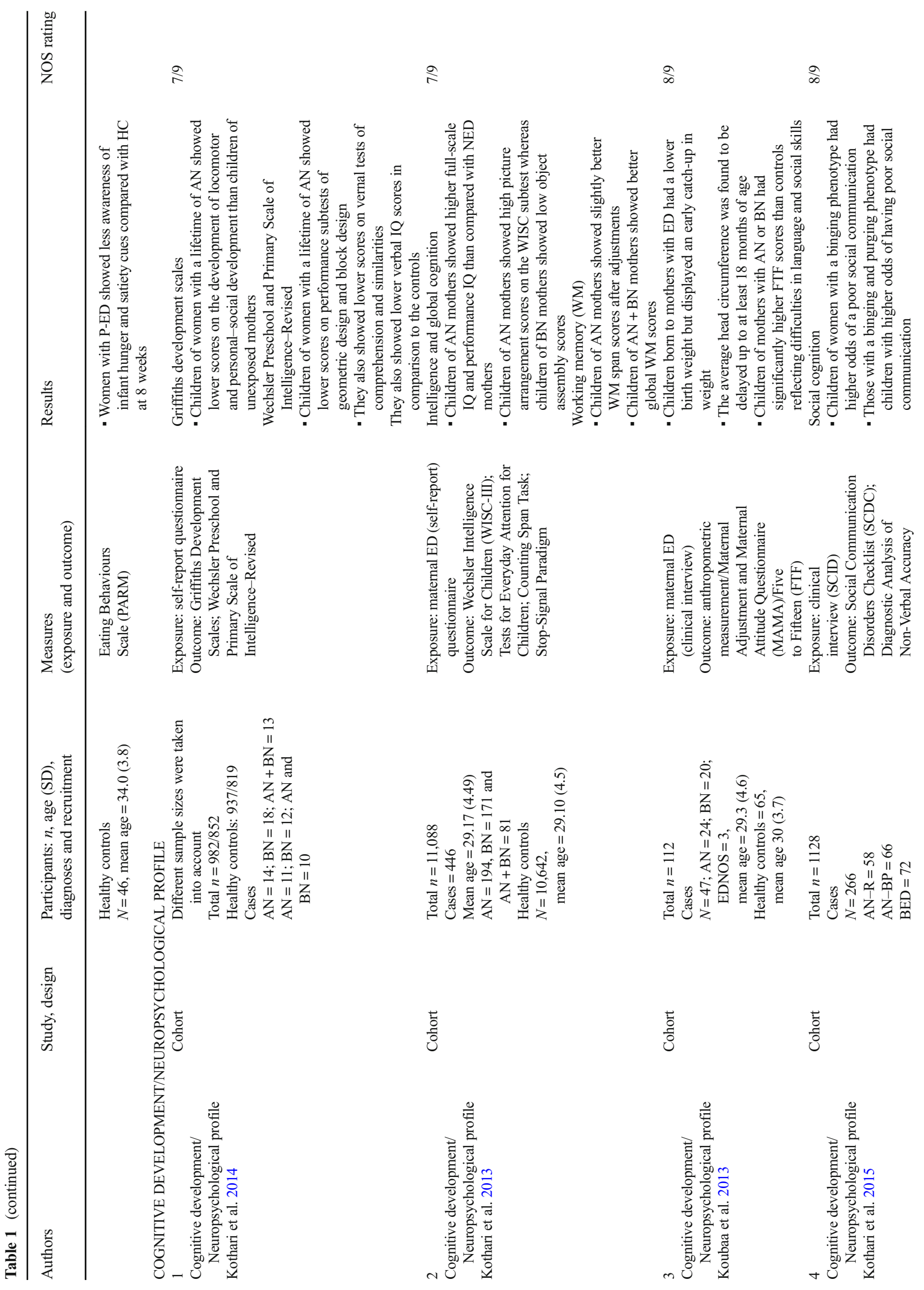




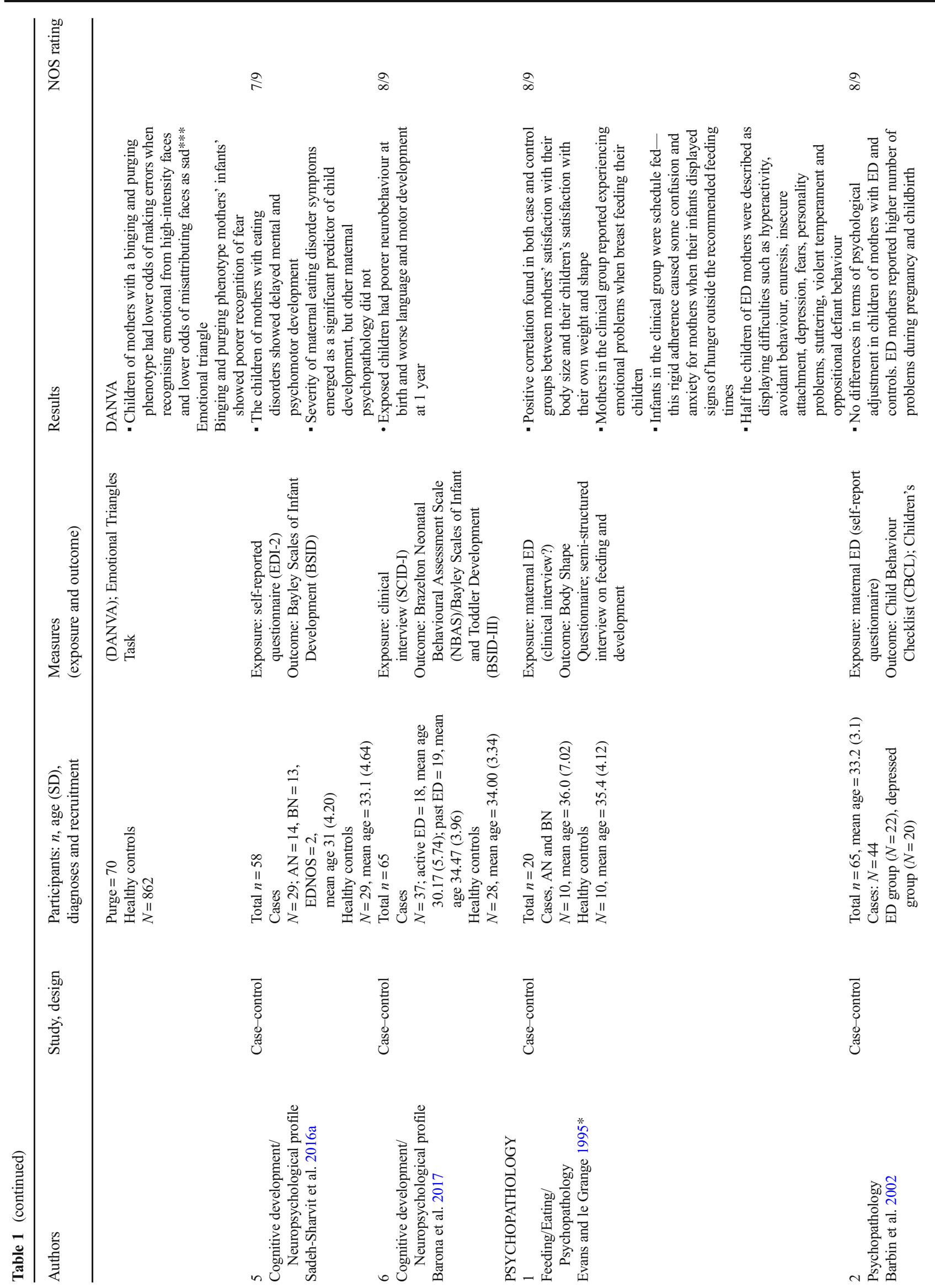




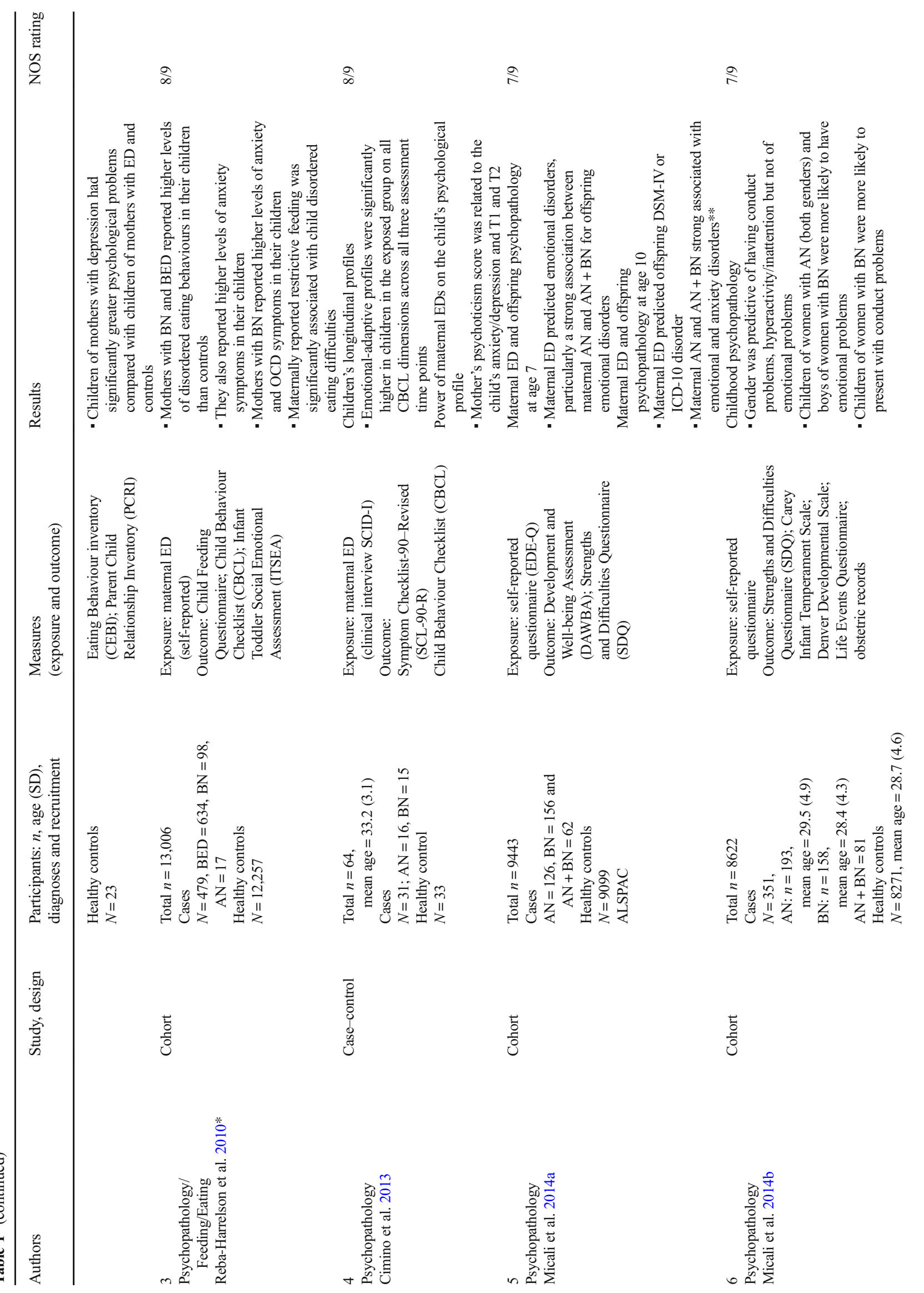




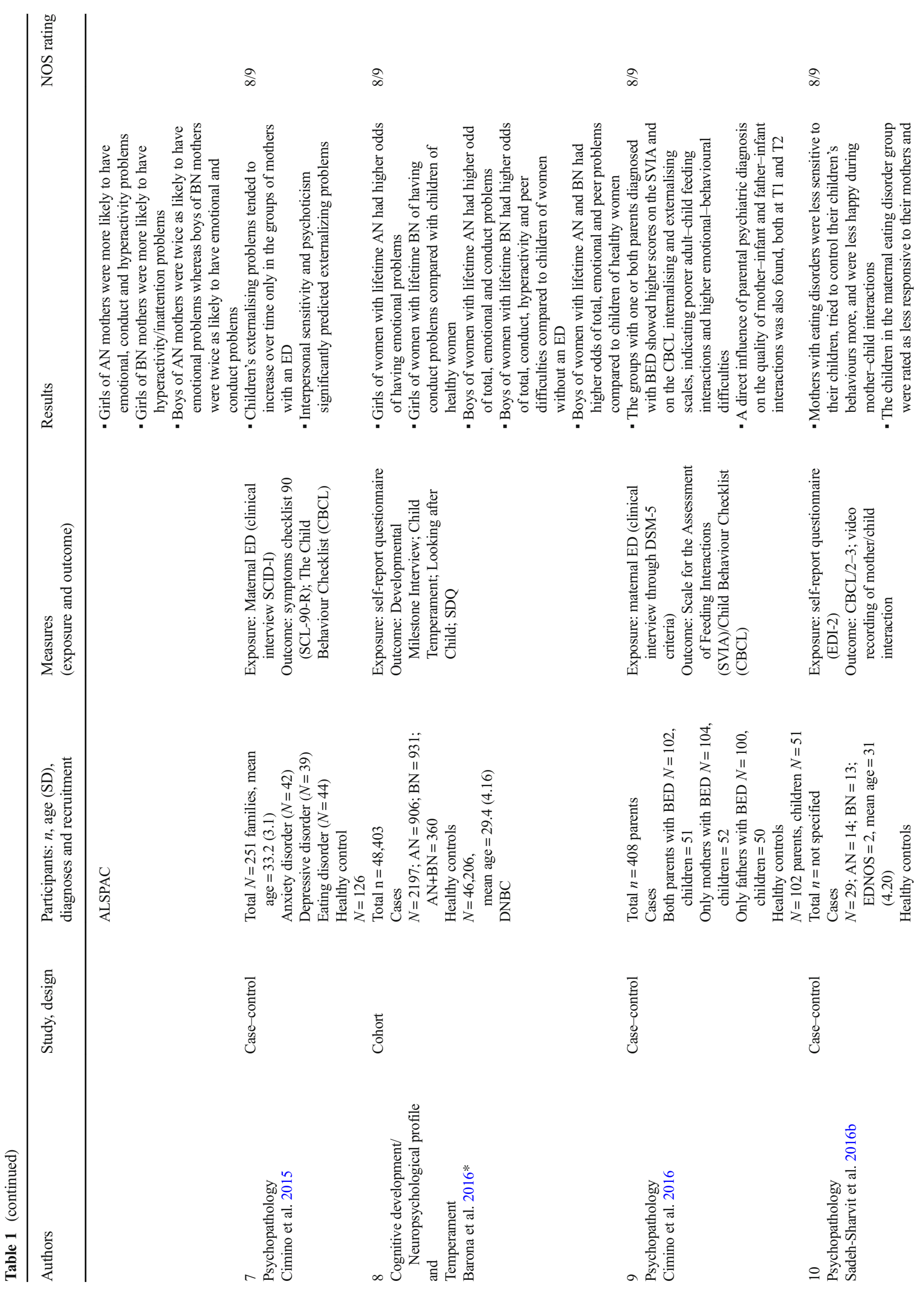




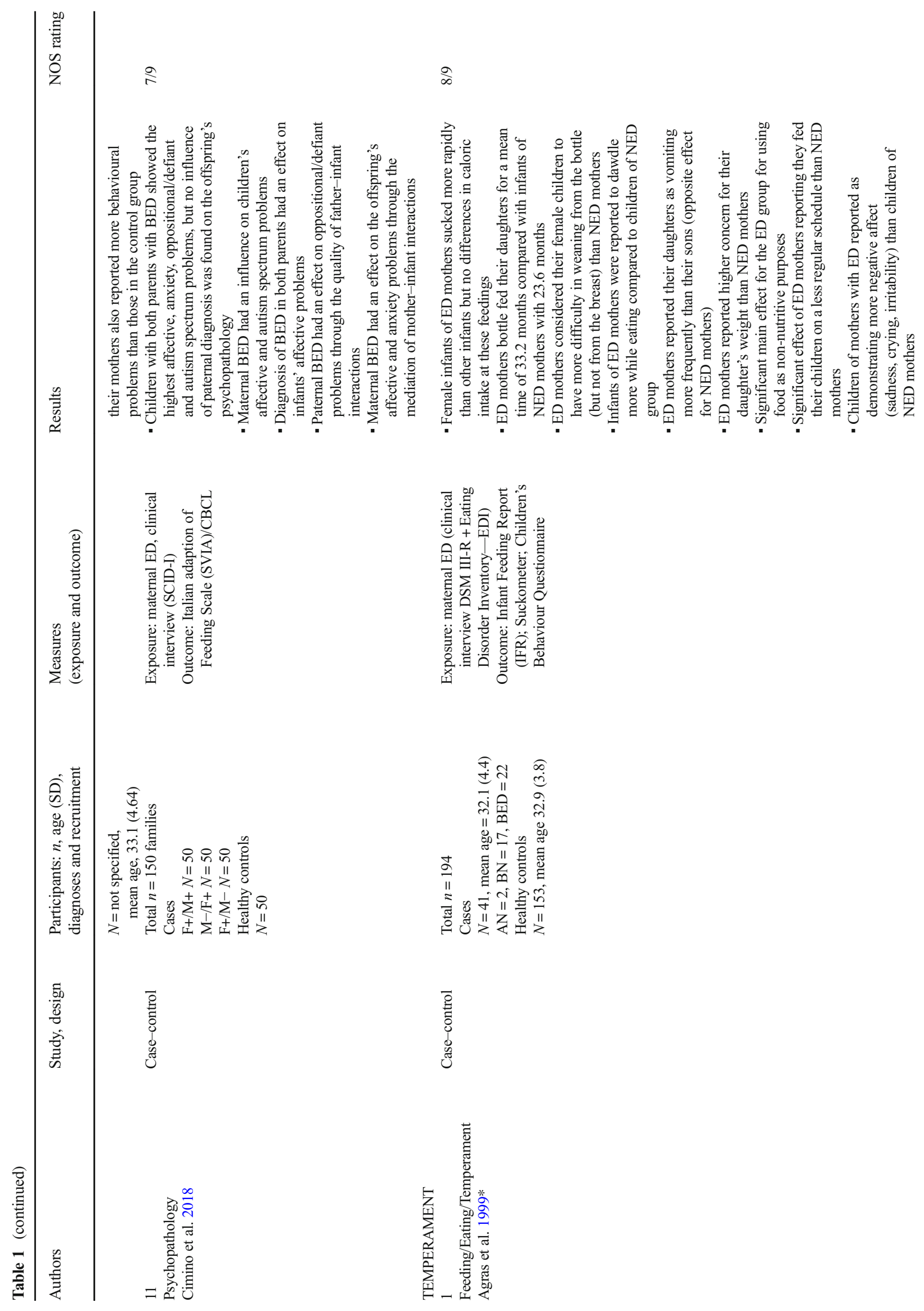




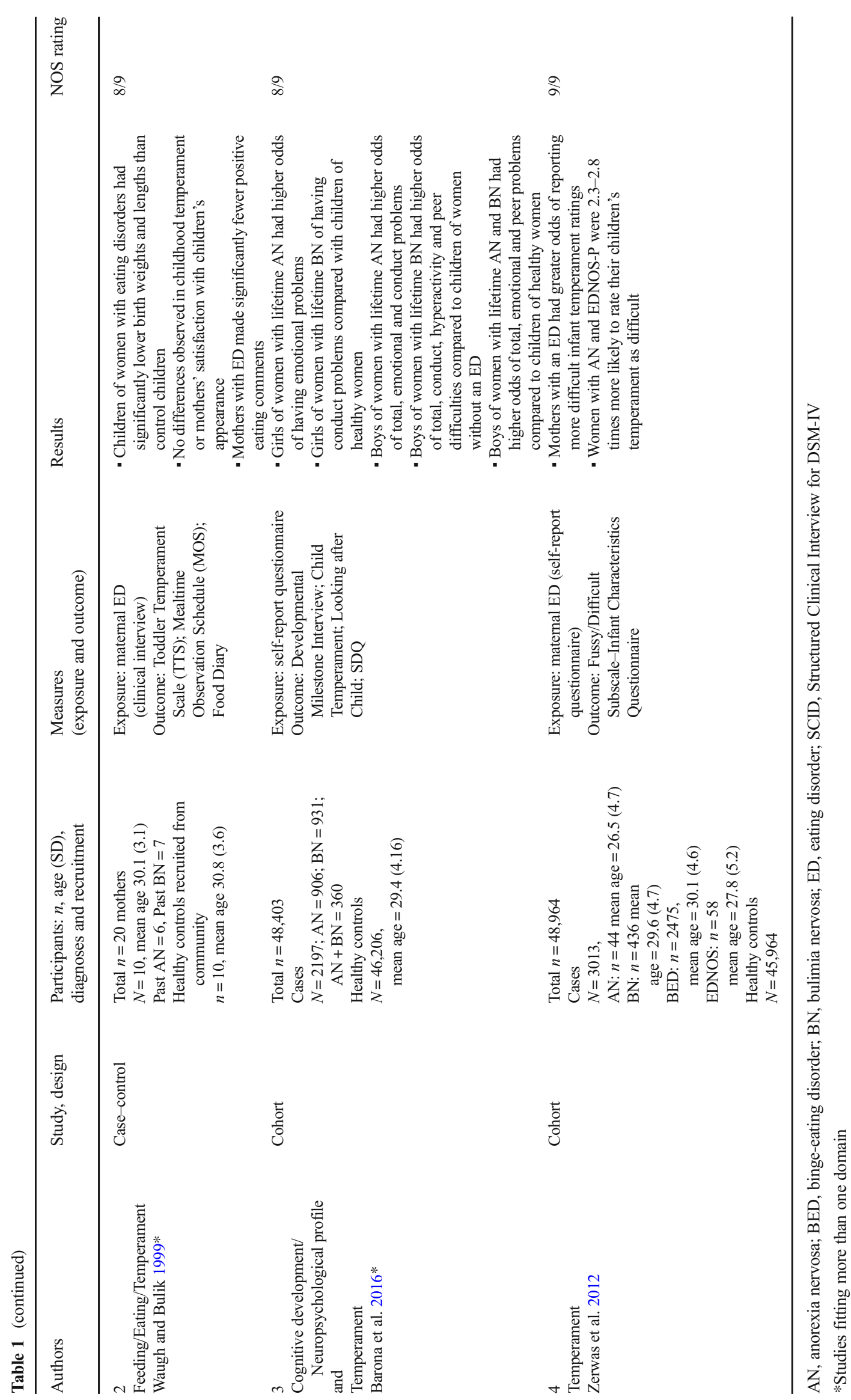




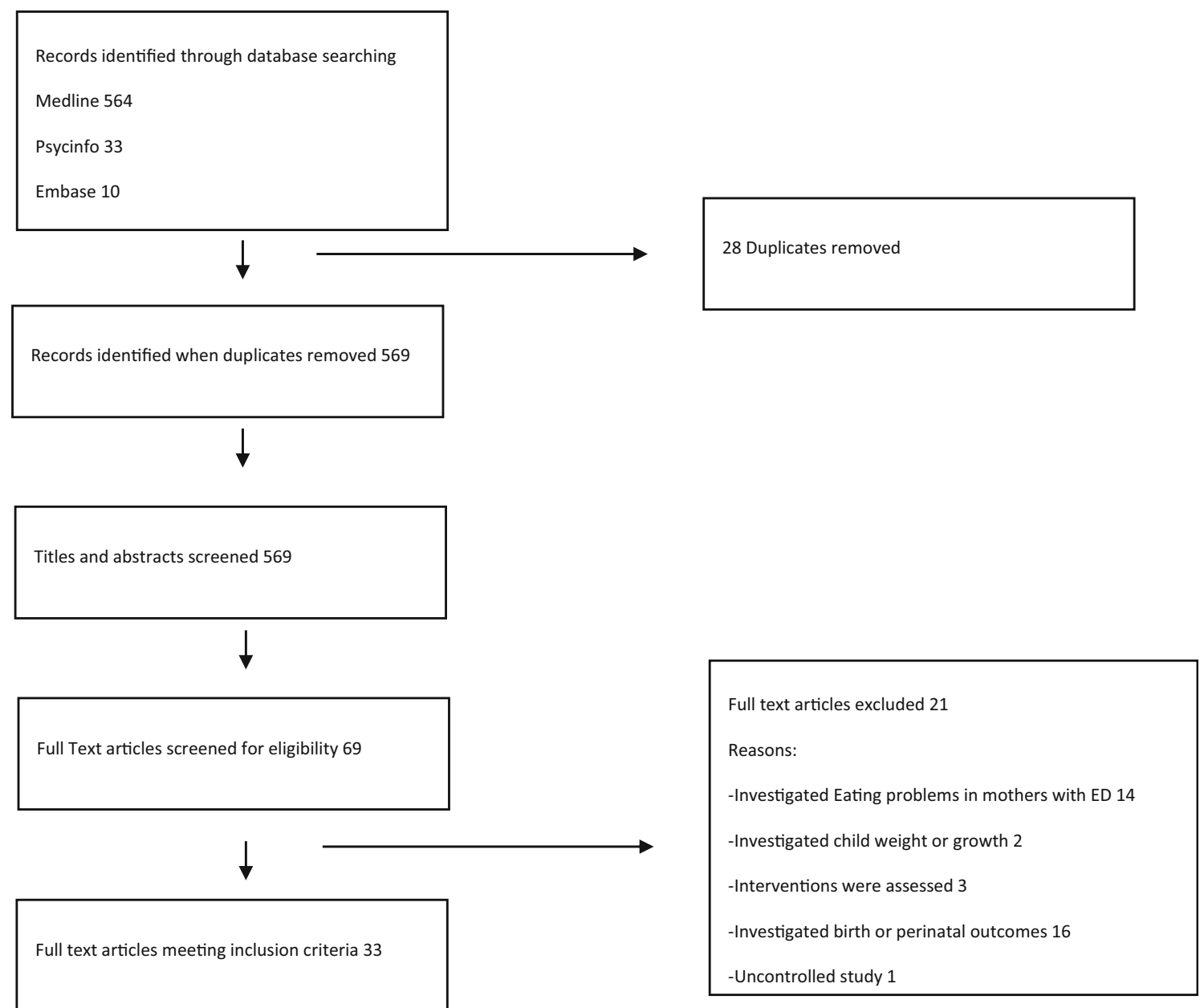

Fig. 1 PRISMA flow diagram showing study selection process

and infant temperament $(n=4)$. Five studies fit more than one domain.

Characteristics of the 34 articles included in the systematic review are shown in Table 1.

\section{Quality assessment}

The research design and content of studies was well executed with over $90 \%$ rated as strong. The four studies rated as moderate were due to (1) poor representativeness of cases, poorly defined controls and ascertainment of exposure; (2) lack of comparability of cases and controls on the basis of design or analysis (Blissett and Meyer 2006); (3) one study being uncontrolled (Hodes et al. 1997); and (4) no description of control group, no mention of history of outcome (Saltzman et al. 2016). It is worth noting that sample size was not accounted for as some studies rated as strong included small sample sizes of less than 10 (Evans and le Grange 1995). Therefore, a strong and positive overall assessment should be interpreted with caution.

\section{Study results}

Feeding outcomes $(n=17)$

Given its relevance, the impact of maternal ED on children's feeding and mealtimes is an area that has received considerable attention. Feeding the infant is a crucial task of parenting not only because it can absorb considerable part of the day in the early stages of life but also because it is one of the most important means of communication between mother and child (Silva et al. 2016).

Review of the present studies showed that mothers with ED might exhibit problems in feeding behaviours with their offspring starting from breast feeding. A number of populationbased studies investigated the impact of ED on breast feeding, yielding discrepant findings (Micali et al. 2011, 2009). A large population-based study showed that women with a history of ED were more likely to start breast feeding and less likely to stop during the first year of the infant life. More specifically, mothers with BN were more likely to continue breast feeding and these differences persisted even after adjusting for 
confounding factors (Micali et al. 2009). A similar study found that women with ED started breast feeding their infants as often as controls; however, they were more likely to interrupt early (Torgersen et al. 2010). Conversely, Nguyen and colleagues found that mothers with a history of ED were slightly less likely to initiate breast feeding, although no longer significant after adjustment (socio-demographics, body mass index (BMI), maternal psychiatric symptoms) (Nguyen et al. 2017).

Although feeding difficulties are common in early stages of the infant's life, mothers with AN reported increased feeding problems including exhaustion during feeding, slow feeding and no established feeding routine (Micali et al. 2011, 2009). On the other hand, infants of women with BN had higher levels of refusal to take solids in comparison to controls (Micali et al. 2009). Blisset and Meyer found similar results with some gender specificity, showing that maternal eating psychopathology predicted food refusal in girls but not boys. Symptoms of low maternal depression combined with high bulimic scores were significantly associated with food refusal in girls (Blissett and Meyer 2006). Conversely, Whelan and Cooper did not find the gender of the child to be related to maternal ED history, nor did it moderate the relationship between feeding difficulties and maternal ED (Whelan and Cooper 2000).

There is a well-known relationship between specific parenting styles in women with EDs and feeding problems in their offspring. An early study found that negative expressed emotions and more intrusive behaviours were more frequent among mothers with ED compared to controls during both mealtime and play (Stein et al. 1994). Mealtime interaction in offspring (ages 1-4) and mothers with ED compared to controls was also investigated by Waugh and Bulik (1999) who found that control mothers made more positive eating comments while mothers with ED tended to be more negative.

Differences between ED diagnoses and their impact on infant feeding problems are worth noting. Saltzman and colleagues found that maternal BED predicted use of more nonresponsive feeding practices (i.e. emotion regulation, restriction for health, pressure to eat and food as reward), indirectly through more distress responses to children's negative emotions. Maternal BED was associated with greater use of distress responses, which indirectly predicted higher child BMI percentile through food as reward feeding practices (Saltzman et al. 2016). Also, mothers with BN or BED were more likely to report higher levels of restrictive feeding styles compared to controls (Reba-Harrelson et al. 2010), and mothers with a history of AN were more likely to use less pressuring feeding strategies compared to controls (de Barse et al. 2015).

Maternal ED can also influence nutritional intake, dietary patterns and diet quality in infants.

Easter and colleagues found that children of mothers with ED reported higher scores on the 'health conscious/ vegetarian' dietary pattern (diet high in vegetarian foods, nuts, salad, rice, pasta and fruits) across all four time periods (ages 3, 4, 7 and 9) when compared with controls (Easter et al. 2013). Furthermore, they showed less adherence to the 'traditional' dietary pattern across all four time points. Energy intake was higher in the $\mathrm{BN}$ and $\mathrm{AN}+\mathrm{BN}$ group, and this intake increased significantly over time for children of mothers with BN (Easter et al. 2013). In another study, Torgersen et al. (2015) found that mothers with BN and BED were less likely to use 'homemade traditional food' than 'commercial jarred baby food' when compared with mothers without ED; however, in women with BED, the associations were significant only before controlling for relevant confounders (Torgersen et al. 2015). Nguyen and colleagues found that children of mothers with life-time ED had higher diet quality at 1 year (Nguyen et al. 2017). Mothers with histories of ED may also be more likely to take 'special approaches' to feeding their children, such as limiting the amount of processed foods or eliminating other types or classes of foods (Hoffman et al. 2014).

Body image distortion, core symptoms of both $\mathrm{AN}$ and BN can also have an impact on feeding practices. In a recent study conducted by our team, we found that women with both past and current ED reported higher concerns about their infant being/becoming overweight compared with controls, respectively, at 8 weeks and 6 months and 6 months only postnatally. Also, women with past ED showed less awareness of infant hunger and satiety cues compared with $\mathrm{HC}$ at 8 weeks (Martini et al. 2018).

\section{Cognitive development and neuropsychological profile $(n=$} 6)

There is a growing evidence to suggest that ED are characterised by a specific neurocognitive profile including alterations in attention, visuospatial ability, memory, social cognition and executive functions, encompassing set shifting and central coherence (Giombini et al. 2018; Lang et al. 2014; Westwood et al. 2016). These profiles observed during active illness were thought to be a complex interplay between risk and protective factors, given the genetic profile and the drive to high educational achievement and perfectionism, common features of ED profile (Bardone-Cone et al. 2010). Also, these might be intermediate phenotypes, an early risk marker that are thought to lie between genetic/biological risk and actual phenotypical manifestations (Micali and Dahlgren 2016).

Research on neuropsychological profiles in children of women with ED aimed mainly at understanding both the impact of maternal ED on their children and to obtain a better understanding of intermediate endophenotypes of ED.

In the study carried out by Kothari et al. (2013), the investigation of neuropsychological profiles showed that children of mothers with AN had high full-scale and performance IQ, 
increased working memory (WM) capacity, better visuospatial functioning and decreased attentional control when compared to controls (Kothari et al. 2013). Another study investigating the early cognitive development (18 months and 4 years) in a sub-set of these children showed that children of women with lifetime AN had difficulties with social understanding, poorer motor skills, planning and abstract reasoning (Kothari et al. 2014). In a recent longitudinal study of children of mothers with ED, we recently found that infants of mothers with ED had poorer language and motor development compared to control mothers. Interestingly, after studying differential outcomes based on active versus past ED, we found that child cognitive difficulties were associated both with maternal active ED and past ED (Barona et al. 2017). Overall, these findings highlight early developmental difficulties in motor and cognitive development in offspring of ED mothers.

The study of later cognitive characteristics suggests a more specific pattern of strengths and difficulties across several domains of cognition, for example, higher IQ, better visuospatial performance and WM in children of mothers with lifetime $\mathrm{AN}$, and poorer visuospatial functioning in children of mothers with lifetime BN (Barona et al. 2017).

Only one study to date has investigated social cognition in children of mothers with ED in mid-childhood and early adolescence, with some evidence of differences between at-risk offspring and controls. In particular, differential facial emotion processing, poorer recognition of fear, and higher scores on the social communication disorders checklist were present in children of mothers with binge eating and purging behaviours, the latter also present in children of mothers with lifetime BED (Kothari et al. 2015).

Finally, in a small longitudinal cohort study, Koubaa and colleagues found that children born to mothers with $\mathrm{AN}$ or BN had significantly higher Five to Fifteen (validated parent questionnaire assessing neurocognitive development) scores than controls reflecting difficulties in language and social skills (Koubaa et al. 2013).

\section{Psychopathology $(N=12)$}

There is strong evidence that parental mental illness is associated with psychopathology in offspring, establishing that children of parents with psychiatric disorders are at higher risk of developing psychopathology themselves (Rasic et al. 2013). Research has also shown that familiar risk is only partly diagnosis-specific meaning that children might develop the same parental diagnosis (homotypic transmission) but may be also at risk for a range of other psychiatric disorders (heterotypic transmission) (Siegenthaler et al. 2012). However, the effect of maternal ED on their offspring psychopathology has received less attention.

Of the studies in this domain, five specifically investigated psychological/emotional development (Barbin et al. 2002;
Cimino et al. 2016, 2013, 2015; Sadeh-Sharvit et al. 2016b) and seven explored general psychopathology (Barona et al. 2016; Cimino et al. 2018; Evans and le Grange 1995; Hodes et al. 1997; Micali et al. 2014a, 2014b; Reba-Harrelson et al. 2010).

A large longitudinal cohort study identified a higher risk for emotional and behavioural disorders in offspring of $\mathrm{ED}$ mothers at an early age (3.5 years). Specifically, the authors identified associations between maternal ED type (AN vs. $\mathrm{BN}$ ) and child psychopathology (emotional vs. behavioural problems), as well as gender differences (Micali et al. 2014b). Emotional difficulties were found in both girls and boys of mothers with AN, while more hyperactivity and peer difficulties were found in both girls and boys of mothers with $\mathrm{BN}$. This study also aimed to understand risk mechanisms and highlighted a mediating role for maternal anxiety and depression in the postpartum. These findings were confirmed and extended in a later study when the same children were aged 7, 10 and 13, where maternal EDs (both AN and BN) strongly predicted emotional and anxiety disorders (Micali et al. 2014a). A recent longitudinal study showed that maternal ED was associated with childhood psychopathology in girls and boys at age 7, both emotional and behavioural problems. Disorder and gender-specific findings across studies point to an effect of maternal lifetime AN on emotional disorders, in particular anxiety, across ages; while maternal BN seems to be associated with hyperactivity, conduct and peer problems (Barona et al. 2016).

These findings support those of case-control studies. In two longitudinal studies using the Child Behaviour Checklist (CBCL), the authors found that children of mothers with ED reported higher externalising and internalising scores from the CBCL compared to controls (Cimino et al. 2015, 2018). The emotional-adaptive profiles of children in the clinical group of mothers with ED scored significantly higher in all dimensions of the CBCL (Cimino et al. 2013). More specifically, externalising problems increased over time (Cimino et al. 2015).

The same authors carried out other two longitudinal studies aimed at investigating the emotional and behavioural profile of children of one or both parents with BED and adult-child feeding interaction (Cimino et al. 2016, 2018). They found that the children with one or both parents diagnosed with BED had higher scores on the internalising and externalising scales, and higher levels of emotional and behavioural difficulties (Cimino et al. 2016). Furthermore, children with both parents with BED showed the highest affective, anxiety, oppositional/defiant, and autism spectrum problems versus children of families with only one BED diagnosed father. Maternal BED was associated with children's affective and autism spectrum problems, and diagnosis of BED in both parents had an effect on infants' affective problems. Paternal BED had an effect on oppositional/defiant problems through the quality of father-infant interactions, and maternal BED 
had an effect on the offspring's affective and anxiety problems through the mediation of mother-infant interactions (Cimino et al. 2018).

On the contrary, Barbin et al. did not find any difference in terms of psychological adjustment on both subscales of internalising and externalising in children of mothers with ED compared to healthy controls (Barbin et al. 2002).

In two early small studies, authors found that half of children of mothers with ED displayed psychiatric problems such hyperactivity, avoidant behaviour, enuresis, insecure attachment, depression, fears, personality problems, stuttering, violent temperament and oppositional defiant behaviour (Evans and le Grange 1995) and OCD (Hodes et al. 1997), respectively.

The latter association has also been found in a more recent large cohort study conducted by Reba-Harrelson and colleagues. The authors found that children of mothers with binge BED or BN were significantly more likely to exhibit symptoms of anxiety compared to children of control group mothers. Children of mothers with BN were also significantly more likely to exhibit obsessive-compulsive symptoms than children of non-eating-disordered mothers. All those with AN, BN or BED were significantly more likely to have children who exhibited symptoms of depression (RebaHarrelson et al. 2010).

Likewise in a small recent study, mothers with ED reported higher levels of behavioural problems in their children compared to control mothers (Sadeh-Sharvit et al. 2016b).

\section{Temperament $(N=4)$}

Temperament is defined as early appearing, biologically rooted, basic personality dimension (Bates et al. 1995). Although temperament is said to be a biological tendency within each child, environmental contexts, especially the social context, interrelate with the genetic tendencies of each child (Shiner et al. 2012).

Mothers with EDs have been shown to be more likely to describe their infant as having a difficult temperament. Compared to women with no history or current EDs, they tend to rate their children as having high levels of difficult temperament (Zerwas et al. 2012) and perceive them as having greater negative affect, that is, demonstrating more sadness, irritability and crying compared to controls (Agras et al. 1999). In a more recent large longitudinal study, we found that mothers with ED were more likely to perceive their children as having a 'difficult temperament' characterised by the child being less happy and active than other children their age, more restless and as having more tantrums and as being less cautious and guarded than other children their age (Barona et al. 2016). On the contrary in an early study, the authors did not observe any difference in childhood temperament between children born from ED mothers and controls (Waugh and Bulik 1999).

\section{Discussion}

The literature regarding the impact of maternal ED on child development has expanded in the last decade. Albeit earlier studies focusing on small clinical samples, larger population-based samples have recently increased our knowledge on the topic.

Overall, the literature suggests that maternal ED impact on child cognitive, psychological and feeding and eating development.

Regarding feeding and eating, research shows that children of mothers with ED tend to experience more difficulties in feeding their children both in infancy and childhood. Although studies on breast feeding yield mixed results, women with ED often report difficulties with this. Throughout toddler years, difficulties such as slow feeding, small quantities feeding and not having established feeding routines emerged as common among ED mothers. Restricting parental feeding styles, negative expressed emotions and intrusive behaviours also appeared to be more frequent in ED mothers compared to controls. The most recent findings (Martini et al. 2018; Saltzman et al. 2016) are in line with earlier research (Stein et al. 1994). To date, it is not possible to disentangle the influence of genetic predisposition versus environmental factors, though likely both have a role. Future research investigating genotype-environment interface is warranted to provide further insight.

Although the current literature is less prominent, available findings shows that a maternal lifetime history of ED may have a negative impact also on children's cognitive, psychological development and psychopathology.

Interestingly, recent studies have identified shared genetic risk between $\mathrm{ED}$ and other psychiatric disorders, i.e. schizophrenia and BED (Solmi et al. 2019) and AN and obsessive compulsive disorder (OCD) but also other positive genetic correlations between AN and schizophrenia and AN and neuroticism (Duncan et al. 2017; Yilmaz et al. 2018). These findings suggest that the genetic risk transmitted will impact on the behavioural, physiological and medical phenotypes expressed in children. Therefore, we might assume that children of AN women have a higher genetic risk of developing a wide range of phenotypes and psychiatric disorders such as psychosis, neuroticism, educational attainment but also lower BMI and lower risk of diabetes. Less is known on cognition and neuropsychological characteristics in offspring of ED mothers prior to the onset of psychopathology, and these might be an important focus of study in at-risk offspring, helping future prevention and early interventions.

\section{Strengths and limitations}

This systematic review has several strengths. First, it is the first systematic review summarising the existing findings from 
1980 until 2018 on the impact of maternal ED on child development, and its findings can be valuable in deriving future hypothesis.

Second, the majority of studies relied on community-based or register-based samples rather than clinical samples; therefore, selection bias in the original studies is likely to be small.

Moreover, if an association between maternal ED and child development has been established in population-based studies, which are more likely to include less severe case of ED, our results are liable to be an underestimation of the effect.

However, some limitations should also have to be taken into account. Some of the studies reviewed above are single findings and need replication. Also, the vast majority of the studies explored mother-child dyad and did not involve the fathers. Although ED have a higher incidence in women than in men, gender ration is less skewed in BED than BN and AN (Hudson et al. 2007) and paternal ED can also have an impact on child development.

Studies showed a high degree of heterogeneity in the way the ED diagnosis is established, ranging from self-reported questionnaires (used in cohort studies such as ALSPAC (Easter et al. 2013; Micali et al. 2009, 2011, 2014a, 2014b, ), DNBC (Barona et al. 2016), Generation R study (de Barse et al. 2015; Nguyen et al. 2017), MoBa (Torgersen et al. 2015)) to structured interviews using both the Diagnostic and Statistical Manual (Agras et al. 1999; Cimino et al. 2016; Evans and le Grange 1995; Stein 1999; Waugh and Bulik 1999; Whelan and Cooper 2000) and SCID I (Barona et al. 2017; Cimino et al. 2015, 2018; Hoffman et al. 2014; Kothari et al. 2015; Martini et al. 2018).

It is important to point out that parental psychopathology does not always impact on child development in a negative way. This might be due to numerous factors including protective family network, child resilience, early access to mental health services, parenting abilities etc.

Future research should focus on the protective factors that moderate the relationship between maternal ED and adverse child outcomes leading to a healthy development of the child. This would shed light into mechanisms that could be potentially directed for intervention. For example, further research could introduce fathers and explore their roles in the family dynamics and in ameliorating, exacerbating or acting independently of the possible influence of a mother with ED.

\section{Conclusion}

In summary, maternal ED have an impact on child psychological, cognitive and eating development, and might affect the development of ED in the offspring. Despite this evidence, little is known on how genetic and environmental factors interplay and affect risk. As maternal psychopathology not always negatively affect child development, future research should focus on resilience and on which protective factors have impact on positive outcome. These factors can be then used as therapeutic and preventative targets.

\section{Compliance with ethical standards}

Conflict of interest The authors declare that they have no competing interests.

Ethical approval The article does not contain any studies with human participants performed by any of the authors.

Open Access This article is licensed under a Creative Commons Attribution 4.0 International License, which permits use, sharing, adaptation, distribution and reproduction in any medium or format, as long as you give appropriate credit to the original author(s) and the source, provide a link to the Creative Commons licence, and indicate if changes were made. The images or other third party material in this article are included in the article's Creative Commons licence, unless indicated otherwise in a credit line to the material. If material is not included in the article's Creative Commons licence and your intended use is not permitted by statutory regulation or exceeds the permitted use, you will need to obtain permission directly from the copyright holder. To view a copy of this licence, visit http://creativecommons.org/licenses/by/4.0/.

\section{References}

Agras S, Hammer L, McNicholas F (1999) A prospective study of the influence of eating-disordered mothers on their children. Int J Eating Disord 25(3):253-262

Bannatyne AJ, Hughes R, Stapleton P, Watt B, MacKenzie-Shalders K (2018) Signs and symptoms of disordered eating in pregnancy: a Delphi consensus study. BMC Pregnancy Childbirth 18(1):1-16. https://doi.org/10.1186/s12884-018-1849-3

Barbin JM, Williamson DA, Stewart TM, Reas DL, Thaw JM (2002) Psychological adjustment in the children of mothers with a history of eating disorders. Eat Weight Disord 7:32-38

Bardone-Cone AM, Sturm K, Lawson MA, Robinson DP, Smith R (2010) Perfectionism across stages of recovery from eating disorders. Int J Eating Disord 43(2):139-148. https://doi.org/10.1002/eat. 20674

Barona M, Nybo Andersen AM, Micali N (2016) Childhood psychopathology in children of women with eating disorders. Acta Psychiatr Scand 134(4):295-304. https://doi.org/10.1111/acps.12616

Barona M, Taborelli E, Corfield F, Pawlby S, Easter A, Schmidt U et al (2017) Neurobehavioural and cognitive development in infants born to mothers with eating disorders. J Child Psychol Psychiatry Allied Discip 58(8):931-938. https://doi.org/10.1111/jcpp.12736

Bates JE, Wachs T, VandenBos G (1995) Trends in research on temperament. Psychiatr Serv 46(7):661-663

Blissett J, Meyer C (2006) The mediating role of eating psychopathology in the relationship between unhealthy core beliefs and feeding difficulties in a nonclinical group. Int J Eat Disord 39:763-771. https:// doi.org/10.1002/eat

Bulik CM, Reba L, Siega-Riz AM, Reichborn-Kjennerud T (2005) Anorexia nervosa: definition, epidemiology, and cycle of risk. Int J Eat Disord 37(SUPPL). https://doi.org/10.1002/eat.20107

Cimino S, Cerniglia L, Paciello M, Sinesi S (2013) A six-year prospective study on children of mothers with eating disorders: the role of paternal psychological profiles. Eur Eat Disord Rev 21:238-246. https://doi.org/10.1002/erv.2218 
Cimino S, Cerniglia L, Paciello M (2015) Mothers with depression, anxiety or eating disorders: outcomes on their children and the role of paternal psychological profiles. Child Psychiatry Hum Dev 46:228236. https://doi.org/10.1007/s10578-014-0462-6

Cimino S, Cerniglia L, Porreca A, Simonelli A, Ronconi L, Ballarotto G (2016) Mothers and fathers with binge eating disorder and their 1836 months old children: a longitudinal study on parent-infant interactions and offspring's emotional-behavioral profiles. Front Psychol 7:1-12. https://doi.org/10.3389/fpsyg.2016.00580

Cimino S, Cerniglia L, Porreca A, Ballarotto G, Marzilli E, Simonelli A (2018) Impact of parental binge eating disorder: exploring children's emotional/behavioral problems and the quality of parent-child feeding interactions. Infant Ment Health J 39(5):552-568. https://doi. org/10.1002/imhj.21732

de Barse LM, Tharner A, Micali N, Jaddoe VVW, Hofman A, Verhulst FC et al (2015) Does maternal history of eating disorders predict mothers' feeding practices and preschoolers' emotional eating? Appetite 85:1-7. https://doi.org/10.1016/j.appet.2014.10.031

Duncan L, Yilmaz Z, Walters R, Goldstein J, Anttila V, Bulik-Sullivan B et al (2017) Genome-wide association study reveals first locus for anorexia nervosa and metabolic correlations. Am J Psychiatr 174(9): 850-858. https://doi.org/10.1176/appi.ajp.2017.16121402. Genome-Wide

Easter A, Howe LD, Tilling K, Schmidt U, Treasure J, Micali N (2014) Growth trajectories in the children of mothers with eating disorders: a longitudinal study. BMJ Open 4(3):1-10. https://doi.org/10.1136/ bmjopen-2013-004453

Easter A, Naumann U, Northstone K, Schmidt U, Treasure J, Micali N (2013) A longitudinal investigation of nutrition and dietary patterns in children of mothers with eating disorders. J Pediatr 163(1):173178.e1. https://doi.org/10.1016/j.jpeds.2012.11.092

Evans J, le Grange D (1995) Body size and parenting in eating disorders: a comparative study of the attitudes of mothers towards their children. Int J Eating Disord 18(1):39-48

Giombini L, Nesbitt S, Cox H, Foxall A, Sharia T, Easter A, Tchanturia K (2018) Cognitive remediation therapy ( CRT ) in a specialist inpatient eating disorder service for children and adolescents : CANCRT study protocol for a pilot randomised controlled trial. Eur Eat Disord Rev (February):1-9. https://doi.org/10.1002/erv.2592

Hodes M, Timimi S, Robinson P (1997) Children of mothers with eating disorders: a preliminary study. Eur Eat Disord Rev 5(1):11-24. https://doi.org/10.1002/(SICI)1099-0968(199703)5:1<11::AIDERV179>3.0.CO;2-7

Hoffman ER, Bentley ME, Hamer RM, Hodges EA, Ward DS, Bulik CM (2014) A comparison of infant and toddler feeding practices of mothers with and without histories of eating disorders. Mater Child Nutr 10(3):360-372. https://doi.org/10.1111/j.1740-8709. 2012.00429.x

Hudson JI, Hiripi E, Pope H, Kessler RC (2007) The prevalence and correlates of eating disorders in the National Comorbidity Survey Replication. Biol Psychiatry 61(3):348-358

Kothari R, Solmi F, Treasure J, Micali N (2013) The neuropsychological profile of children at high risk of developing an eating disorder. Psychol Med 43:1543-1554. https://doi.org/10.1017/ S0033291712002188

Kothari R, Rosinska M, Treasure J, Micali N (2014) The early cognitive development of children at high risk of developing an eating disorder. Eur Eat Disord Rev 22:152-156. https://doi.org/10.1002/erv. 2274

Kothari R, Barona M, Treasure J, Micali N (2015) Social cognition in children at familial high-risk of developing an eating disorder. Front Behav Neurosci 9:1-17. https://doi.org/10.3389/fnbeh.2015.00208

Koubaa S, Hallstrom T, Hagenas L, Hirschberg AL (2013) Retarded head growth and neurocognitive development in infants of mothers with a history of eating disorders: longitudinal cohort study. BJOG 120: 1413-1421. https://doi.org/10.1111/1471-0528.12370
Lang K, Lopez C, Stahl D, Tchanturia K, Treasure J, Lang K et al (2014) Central coherence in eating disorders: an updated systematic review and meta-analysis. World J Biol Psychiatry:2975. https://doi.org/10. 3109/15622975.2014.909606

Martini MG, Taborelli E, Schmidt U, Treasure J, Micali N (2018) Infant feeding behaviours and attitudes to feeding amongst mothers with eating disorders: a longitudinal study. Eur Eat Disord Rev:1-10. https://doi.org/10.1002/erv.2626

Mazzeo SE, Zucker NL, Gerke CK, Mitchell KS, Bulik CM (2005) Parenting concerns of women with histories of eating disorders. Int J Eat Disord 37(SUPPL):77-79. https://doi.org/10.1002/eat. 20121

Micali N, Treasure J (2009) Biological effects of a maternal ED on pregnancy and foetal development: a review. Eur Eat Disord Rev 17: 448-454. https://doi.org/10.1002/erv.963

Micali N, Simonoff E, Treasure J (2009) Infant feeding and weight in the first year of life in babies of women with eating disorders. J Pediatr 154:55-60. https://doi.org/10.1016/j.jpeds.2008.07.003

Micali N, Simonoff E, Stahl D, Treasure J (2011) Maternal eating disorders and infant feeding difficulties: maternal and child mediators in a longitudinal general population study. J Child Psychol Psychiatry 52(7):800-807. https://doi.org/10.1111/j.1469-7610.2010.02341.x

Micali N, De Stavola B, Ploubidis GB, Simonoff E, Treasure J (2014a) The effects of maternal eating disorders on offspring childhood and early adolescent psychiatric disorders. Int J Eat Disord 47(4):385393. https://doi.org/10.1002/eat.22216

Micali N, Stahl D, Treasure J, Simonoff E (2014b) Childhood psychopathology in children of women with eating disorders: understanding risk mechanisms. J Child Psychol Psychiatry 55(2):124-134. https:// doi.org/10.1111/jcpp.12112

Micali N, Dahlgren CL (2016) All that glisters is not an endophenotype: rethinking endophenotypes in anorexia nervosa. Eur Child Adolesc Psychiatry 25(11):1149-1150. https://doi.org/10.1007/s00787-0160910-x

Moher D, Liberati A, Tetzlaff J, Altman DG, Group, T. P (2009) Preferred reporting items for systematic reviews and meta-analyses: the PRISMA statement. PLoS Med 6(7):1-6. https://doi.org/10.1371/ journal.pmed.1000097

Nguyen AN, de Barse LM, Tiemeier H, Jaddoe VWV, Franco OH, Jansen PW, Voortman T (2017) Maternal history of eating disorders: diet quality during pregnancy and infant feeding. Appetite 109:108-114. https://doi.org/10.1016/j.appet.2016.11.030

Park R, Senior R, Stein A (2003) The offspring of mothers with eating disorders. Eur Child Adolesc Psychiatry 12:110-119. https://doi. org/10.1007/s00787-003-1114-8

Patel P, Wheatcroft R, Park R, Stein A (2002) The children of mothers with eating disorders. Clin Child Fam Psychol Rev 5(1):1-19

Ramchandani P, Stein A (2003) The impact of parental psychiatric disorder on children. BMJ 327(August):242-243

Rasic D, Hajek T, Alda M, Uher R (2013) Risk of mental illness in offspring of parents with schizophrenia, bipolar disorder and major depressive disorder: a meta-analysis of family high-risk studies. Compr Psychiatry 54:e34-e40. https://doi.org/10.1016/j. comppsych.2013.07.057

Reba-Harrelson L, Von Holle A, Hamer RM, Torgersen L, ReichbornKjennerud T, Bulik CM (2010) Patterns of maternal feeding and child eating associated with eating disorders in the Norwegian mother and child cohort study (MoBa). Eat Behav 11(1):54-61

Sadeh-Sharvit, S., Levy-Shiff, R., \& Lock, J. D. (2016a). Maternal eating disorder history and toddlers' neurodevelopmental outcomes: A brief report. Eating Disorders. 24(2):198-205. https://doi.org/10. 1080/10640266.2015.1064280

Sadeh-Sharvit S, Levy-Shiff R, Arnow KD, Lock JD (2016b) The interactions of mothers with eating disorders with their toddlers: identifying broader risk factors. Attach Hum Dev 18(4):418-428. https:// doi.org/10.1080/14616734.2016.1164201 
Saltzman JA, Pineros-Leano M, Liechty JM, Bost KK, Fiese BH, Harrison $\mathrm{K}$ et al (2016) Eating, feeding, and feeling: emotional responsiveness mediates longitudinal associations between maternal binge eating, feeding practices, and child weight. Int J Behav Nutr Phys Act 13(1):1-14. https://doi.org/10.1186/s12966-016-0415-5

Shiner RL, Buss KA, Mcclowry SG, Putnam SP, Saudino KJ, Zentner M (2012) What is temperament now? Assessing progress temperament research on the twenty-fifth anniversary of Goldsmith et al. Child Dev Perspect 6(4):436-444. https://doi.org/10.1111/j.1750-8606. 2012.00254.x

Siegenthaler E, Munder T, Egger M (2012) Effect of preventive interventions in mentally ill parents on the mental health of the offspring: systematic review and meta-analysis. JAAC 51(1):8-17. https://doi. org/10.1016/j.jaac.2011.10.018

Silva, G., Costa, K., \& Giugliani, E. (2016). Infant feeding: Beyond the nutritional aspects. Jornal de Pediatria (Rio J) 92(3):S2-S7. https:// doi.org/10.1016/j.jped.2016.02.006

Solmi F, Mascarell MC, Zammit S, Kirkbride JB, Lewis G (2019) Polygenic risk for schizophrenia, disordered eating behaviours and body mass index in adolescents. Br J Psychiatry 3(December 1992): 1-6. https://doi.org/10.1192/bjp.2019.39

Stein A, Woolley H, Cooper S, Fairburn C (1994) An observational study of mothers with eating disorders and their infants. J Child Psychol Psychiatry Allied Discip 35(4):733-748

Stein A, Woolley H, McPherson K (1999) Conflict between mothers with eating disorders and their infants during mealtimes. Br J Psychiatry 175:455

Torgersen L, Ystrom E, Haugen M, Meltzer HM, Von Holle A, Berg CK et al (2010) Breastfeeding practice in mothers with eating disorders. Mater Child Nutr 6(3):243-252. https://doi.org/10.1111/j.17408709.2009.00208.x
Torgersen L, Ystrom E, Siega-Riz AM, Berg CK, Zerwas SC, ReichbornKjennerud T, Bulik CM (2015) Maternal eating disorder and infant diet. A latent class analysis based on the Norwegian mother and child cohort study (MoBa). Appetite 84:291-298. https://doi.org/ 10.1016/j.appet.2014.10.009

Watson HJ, O'Brien A, Sadeh-Sharvit S (2018) Children of parents with eating disorders. Curr Psychiatry Rep 20(11):101. https://doi.org/10. 1007/s11920-018-0970-3

Waugh E, Bulik CM (1999) Offspring of women with eating disorders. Int J Eating Disord 25(2):123-133

Westwood H, Stahl D, Mandy W, Tchanturia K (2016) The set-shifting profiles of anorexia nervosa and autism spectrum disorder using the Wisconsin card sorting test: a systematic review and meta-analysis. Psychol Med 46:1809-1827. https://doi.org/10.1017/ S0033291716000581

Whelan E, Cooper PJ (2000) The association between childhood feeding problems and maternal eating disorder: a community study. Psychol Med 30:69-77

Yilmaz Z, Halvorsen M, Bryois J, et al. (2018). Eating Disorders Working Group of the Psychiatric Genomics Consortium, Tourette Syndrome/Obsessive-Compulsive Disorder Working Group of the Psychiatric Genomics Consortium. Examination of the shared genetic basis of anorexia nervosa and obsessive-compulsive disorder. Mol Psychiatry. https://doi.org/10.1038/s41380-018-0115-4

Zerwas S, Von Holle A, Torgersen L, Reichborn-kjennerud T, Stoltenberg C, Bulik CM (2012) Maternal eating disorders and infant temperament: findings from the Norwegian mother and child cohort study. Int J Eat Disord 45:546-555. https://doi.org/10.1002/eat.20983

Publisher's note Springer Nature remains neutral with regard to jurisdictional claims in published maps and institutional affiliations. 